\title{
Outer Membrane Vesicles (OMVs) of Gram-negative Bacteria: A Perspective Update
}

\author{
Arif Tasleem Jan * \\ Department of Medical Biotechnology, Yeungnam University, Gyeongsan, South Korea
}

Outer Membrane Vesicles (OMVs) of Gram-negative bacteria are spherical membraneenclosed entities of endocytic origin. Reported in the consortia of different bacterial species, production of OMVs into extracellular milieu seems essential for their survival. Enriched with bioactive proteins, toxins, and virulence factors, OMVs play a critical role in the bacteria-bacteria and bacteria-host interactions. Emergence of OMVs as distinct cellular entities helps bacteria in adaptating to diverse niches, in competing with other bacteria to protect members of producer species and more importantly play a crucial role in host-pathogen interaction. Composition of OMV, their ability to modulate host immune response, along with coordinated secretion of bacterial effector proteins, endows them with the armory, which can withstand hostile environments.

OPEN ACCESS

Edited by:

Ramin M. Hakami,

George Mason University,

United States

Reviewed by:

Giovanna Batoni,

University of Pisa, Italy Leonid Margolis, National Institutes of Health,

United States

*Correspondence:

Arif Tasleem Jan atasleem@gmail.com

Specialty section: This article was submitted to

Infectious Diseases,

a section of the journal

Frontiers in Microbiology

Received: 15 January 2017 Accepted: 26 May 2017

Published: 09 June 2017

Citation:

Jan AT (2017) Outer Membrane Vesicles (OMVs) of Gram-negative

Bacteria: A Perspective Update.

Front. Microbiol. 8:1053.

doi: 10.3389/fmicb.2017.01053
Study of the OMV production under natural and diverse stress conditions has broadened the horizons, and also opened new frontiers in delineating the molecular machinery involved in disease pathogenesis. Playing diverse biological and pathophysiological functions, OMVs hold a great promise in enabling resurgence of bacterial diseases, in concomitance with the steep decline in the efficiency of antibiotics. Having multifaceted role, their emergence as a causative agent for a series of infectious diseases increases the probability for their exploitation in the development of effective diagnostic tools and as vaccines against diverse pathogenic species of Gram-negative origin.

Keywords: Gram-negative bacteria, immune system, Outer Membrane Vesicles (OMVs), pathogenesis, vaccines

\section{INTRODUCTION}

The era of existence of prokaryotes, as autonomous structures has prevailed for a long time. In comparison with the the individual survival traits with few interactions and no compartmentalization (Manning and Kuehn, 2013), a different group of bacteria has emerged with survival strategies similar to the eukaryotes (Raymond and Bonsall, 2013; Spitzer and Poolman, 2013). With ordered structural organization, fine-tuned physiology, and interactive social behavior, a paradigm shift for better survival is observed in bacteria. Of the differently adapted modes, production of Outer Membrane Vesicles (OMVs) by Gram-negative bacteria, plays a prominent role in interaction among themselves or with the host (Bonnington and Kuehn, 2014; Haurat et al., 2015).

Outer Membrane Vesicles are enriched with proteins that enhance their invasive abilities, thereby promoting efficient internalization of OMVs at the host interface. The best examples include, outer membrane (OM) localized invasins, IpaB, IpaC, and IpaD of Shigella flexneri and Ail protein of Escherichia coli (Kuehn and Kesty, 2005). OM proteins OspA and OspB attribute 
adhesive properties to OMVs, and thus enhance binding ability of bacteria to host cell receptors (Shoberg and Thomas, 1993). After adherence to host cells, evasion of the host defense system, or the modulation of the host immune responses, is triggered due to the secretion of toxins such as shiga toxin (Stx1 and Stx2), vacuolating toxin (VacA), heat labile toxin (LT), cholera toxin (CT), etc., and virulence factors such as proteases, glycoproteins, etc. (Ellis and Kuehn, 2010; Chattopadhyay and Jaganandham, 2015). Summary of bacterial OMV production, their properties and functional roles, in bacteria-bacteria and host-bacteria interactions, have been provided in Table $\mathbf{1}$.

In addition to their role in interspecific competition, release of OMVs greatly enhances the survival scenario for a bacterium by subduing effects of bacteriophages and antimicrobial peptides, during the combat (Manning and Kuehn, 2011). They also have a role as a signaling molecule, rendering help by abetting inter- and intra-species communication. Despite this, exosome production, loading of cellular components as cargo, conditions that promote their formation and the role it plays under different circumstances, is yet not clearly established. Hitherto, a lacuna in our understanding of the molecular mechanisms for OMV formation, hampers to ascertain their physiological relevance in vivo. In this review, multifaceted aspects of OMV production - their biogenesis, cargo selection and secretory mechanisms, physiological and pathological functions - with respect to the progression of diseases, and possibility of exploiting OMVs in the development of effective diagnostic tools, have been discussed. It is anticipated that the study will broaden our understanding of the OMV biology and will confer new avenues in the use of OMVs for diverse biotechnological applications.

\section{OUTER MEMBRANE VESICLES}

Outer Membrane Vesicles are small, spherically bilayered (100-300 $\mathrm{nm}$ ) vesicles released into extracellular milieu from the OM of Gram-negative bacteria (Beveridge, 1999). Several bacterial species have been reported to produce OMVs, such as Escherichia coli (McBroom and Kuehn, 2007; Schwechheimer and Kuehn, 2015), Pseudomonas aeruginosa (Bauman and Kuehn, 2006), Shigella sp. (Kadurugamuwa and Beveridge, 1999), Salmonella sp. (Elhenawy et al., 2016), Helicobacter pylori (Fiocca et al., 1999; Turner et al., 2015), Campylobacter jejuni (Lindmark et al., 2009; Elmi et al., 2012), Borrelia burgdorferi (Dorward et al., 1991; Shoberg and Thomas, 1993), Vibrio sp. (Chatterjee and Chaudhuri, 2011), and Neisseria sp. (Devoe and Gilchrist, 1973; Pettit and Judd, 1992) They carry lipopolysaccharides (LPS), phospholipids, peptidoglycan, outer membrane proteins (OMPs), cell wall components, proteins (periplasmic, cytoplasmic, and membrane-bound), nucleic acids (DNA, RNA), ion metabolites and signaling molecules as cargo to them (Lindmark et al., 2009; Koeppen et al., 2016; Vanaja et al., 2016). Owing to the nature of cargo transference, they are anticipated to play a role in the bacterial adherence with the host. They are also involved in stress responses, which involves biofilm formation, inter- and intraspecies delivery of molecules, resistance against antibiotics and modulation of the host immune response.

The ability of OMVs to transfer biological molecules to the host cell, makes their production purposeful among Gram-negative bacteria. Apart from their role in bacterial communication, transfer of virulence factors as cargoes to OMVs, enhances bacterial survival inside the host (Ellis and Kuehn, 2010; Chattopadhyay and Jaganandham, 2015). The development of secretory systems (I - VI) in Gram-negative bacteria has helped in secretion of virulence factors across the bacterial envelope into the extracellular space. Secreted as distinct entities, OMV mediated transfer of virulence factors, adhesion molecules, toxins and other immunomodulatory compounds, constitutes a separate secretory system, that operates in Gram-negative bacteria to gain access to host tissues and bloodstream.

\section{PRODUCTION OF OMVs}

Production of OMVs under in vitro conditions has been reported during the bacterial growth on solid and in liquid media, in biofilms (Schooling and Beveridge, 2006; Klimentova and Stulik, 2015), and also during intracellular infections (Namork and Brandtzaeg, 2002; Unal et al., 2011). As growth conditions have significant influence on the vesiculation process, late grown cells display maximum OMV yields (Klimentova and Stulik, 2015). However, cell death which unavoidably happens during the later stages of the bacterial growth, causes contamination with membrane components and cytosolic proteins. In addition, nutrient unavailability and increased waste disposal at later stages of progressive growth, affects composition profile of OMVs both qualitatively and quantitatively (Tashiro et al., 2010; McCaig et al., 2013; Klimentova and Stulik, 2015). Representing a mechanism to alleviate stress, factors such as temperature, nutrient depletion and exposure to antibiotics, increases packaging and release of the materials (Collins, 2011; Klimentova and Stulik, 2015). Given the fact that inside ambience of host cells remains harsh, host-pathogen interactions itself modifies the composition and production of OMVs (Kuehn and Kesty, 2005). In short, changes in the dynamics of OMVs, with regard to the varying nature of its contents during different growth stages, affects their fate and biological functioning.

\section{BIOGENESIS OF OMVs}

Maintaining viability during vesicle formation makes process of vesiculation complex and elusive. In light of the evidence generated through various biochemical and genetic studies, several models for the mechanistic production of OMVS have been put forth. Previous studies - by Burdett and Murray (1974) and Hoekstra et al. (1976) - on the biogenesis of OMVs suggest that reduction in the cross-linking between peptidoglycan (PG) and OM triggers their formation (Burdett and Murray, 1974; Hoekstra et al., 1976). As lipoprotein Lpp contributes to OM-PG linkage, it was hypothesized, that hypervesiculation 
TABLE 1 | Bacterial species showing OMV production.

\begin{tabular}{|c|c|c|c|c|}
\hline S. No & Bacterial species & $\begin{array}{l}\text { Virulence factors as OMV } \\
\text { component }\end{array}$ & Associated function & Reference \\
\hline 1 & $\begin{array}{l}\text { Escherichia coli [Enterotoxigenic } \\
\text { E. coli (ETEC), Shiga toxin } \\
\text { producing E. coli (STEC), } \\
\text { Enterohemorrhagic E. coli } \\
(\text { EHEC)] }\end{array}$ & $\begin{array}{l}\text { Heat labile enterotoxin (LT), Shiga toxin, } \\
\text { Cytolysin A (ClyA) }\end{array}$ & $\begin{array}{l}\text { Pore forming ability, enterotoxic and } \\
\text { vacuolating activity, cytotoxicity }\end{array}$ & $\begin{array}{l}\text { Kolling and Matthews, 1999; } \\
\text { Horstman and Kuehn, 2000; } \\
\text { Yokoyama et al., 2000; Wai et al., } \\
\text { 2003; Kuehn and Kesty, 2005; } \\
\text { Kwon et al., 2009; Mendez et al., } \\
\text { 2012; Jun et al., } 2013\end{array}$ \\
\hline 3 & Pseudomonas aeruginosa & $\begin{array}{l}\text { Alkaline phosphatase, Phospholipase C } \\
\text { Protease, Hemolysin, Pseudomonas } \\
\text { quinolone signal (PQS), Cif, hydrolases }\end{array}$ & $\begin{array}{l}\text { In vitro enzyme activities, cytokine } \\
\text { stimulation, bactericidal quinolines }\end{array}$ & $\begin{array}{l}\text { Kadurugamuwa and Beveridge, } \\
\text { 1995, 1996; Li et al., 1998; } \\
\text { Mashburn and Whiteley, 2005; } \\
\text { Mashburn-Warren et al., 2008; } \\
\text { Bomberger et al., 2009; Ellis et al., } \\
\text { 2010; Choi et al., 2011; Toyofuku } \\
\text { et al., } 2012\end{array}$ \\
\hline 5 & Shigella flexneri & Invasion plasmid antigens (IpaB, C,D) & Invasion of host tissue & $\begin{array}{l}\text { Kadurugamuwa and Beveridge, } \\
1998\end{array}$ \\
\hline 6 & Shigella dysenteriae & Shiga toxin (Stx) & Cytotoxicity, host cell apoptosis & Dutta et al., 2004 \\
\hline 7 & Salmonella typhi & Outer membrane protein (OmpC), ClyA & Pore forming activity & Bergman et al., 2005 \\
\hline 8 & Treponema denticola & Proteases, Dentilisin & $\begin{array}{l}\text { Chymotryptic activity, disruption of } \\
\text { tight junctions }\end{array}$ & Rosen et al., 1995; Chi et al., 2003 \\
\hline 9 & Neisseria meningitis & NarE, NipB, PorA, B & $\begin{array}{l}\text { Cytokine production, fibrinolytic } \\
\text { activity, adherence to host cells }\end{array}$ & $\begin{array}{l}\text { Ferrari et al., 2006; Vipond et al., } \\
\text { 2006; Massari et al., 2010; Van De } \\
\text { Waterbeemd et al., } 2013\end{array}$ \\
\hline 10 & Bordetella pertussis & $\begin{array}{l}\text { Pertussis toxin (Ptx), Adenylate cyclase } \\
\text { hemolysin }\end{array}$ & Cytotoxicity & Hozbor et al., 1999 \\
\hline 15 & Moraxella catarrhalis & Ubiquitous surface protein (UspA1, A2) & Complement binding & $\begin{array}{l}\text { Tan et al., 2007; Vidakovics et al., } \\
2010\end{array}$ \\
\hline 16 & Acinetobacter baumannii & $\begin{array}{l}\text { Outer membrane protein (AbOmpA), } \\
\text { PAMPS (LPS, flagellin),Proteases, } \\
\text { Phospholipases, SOD, Catalase }\end{array}$ & $\begin{array}{l}\text { Binding to host tissues, } \\
\text { Immunomodulatory effect, enzyme } \\
\text { activity }\end{array}$ & $\begin{array}{l}\text { Kwon et al., 2009; Mendez et al., } \\
\text { 2012; Moon et al., 2012; Jun et al., } \\
\text { 2013 }\end{array}$ \\
\hline 17 & Campylobacter jejuni & Cytolethal distending toxin (CDT) & $\begin{array}{l}\text { Adhesion and invasion, } \\
\text { immunomodulatory effect }\end{array}$ & Elmi et al., 2012; Jang et al., 2014 \\
\hline 18 & Porphyromonas gingivalis & $\begin{array}{l}\text { CTD family proteins such as gingipains } \\
\text { (RgpA, RgpB, Kgp) }\end{array}$ & $\begin{array}{l}\text { Adherence, host tissue Invasion, } \\
\text { immune evasion }\end{array}$ & Veith et al., 2014 \\
\hline 19 & Yersinia pestis & $\begin{array}{l}\text { Adhesin Ail, Protease Pla, F1 outer } \\
\text { fimbrial antigen }\end{array}$ & $\begin{array}{l}\text { Complement binding, enzyme } \\
\text { activity }\end{array}$ & Eddy et al., 2014 \\
\hline 20 & $\begin{array}{l}\text { Cronobacter sp. [C. sakazakii, C. } \\
\text { turicensis, C. malonaticus] }\end{array}$ & $\begin{array}{l}\text { Outer membrane protein (OmpA and } \\
\text { OmpX) }\end{array}$ & Binding to host cell receptors & Kothary et al., 2017 \\
\hline
\end{tabular}

could arise due to a mutation in the lpp gene (Wensink and Witholt, 1981; Bernadac et al., 1998; Cascales et al., 2002). vfgl, a different lipoprotein involved in the synthesis and degradation of PG, is associated with OMV production in E. coli (AIEC) and E. coli K12 strain (Rolhion et al., 2005). Contribution of $v f g l$ in OMV production is presumably linked with the increase of PG production or via down-regulation of lytic transglycosylases, which are associated with the maintenance of turgor pressure on OM (Eggert et al., 2001; Rolhion et al., 2005). Increase in the number of OMVs produced as blebs to OM (Figure 1), relieves cell of the turgor pressure exerted by PG and muramic acid during cell wall synthesis. Although biochemical screening has revealed that OMVs and OM share a similar protein profile, yet, it remains unclear, how cytosolic molecules are packaged to OMVs. 


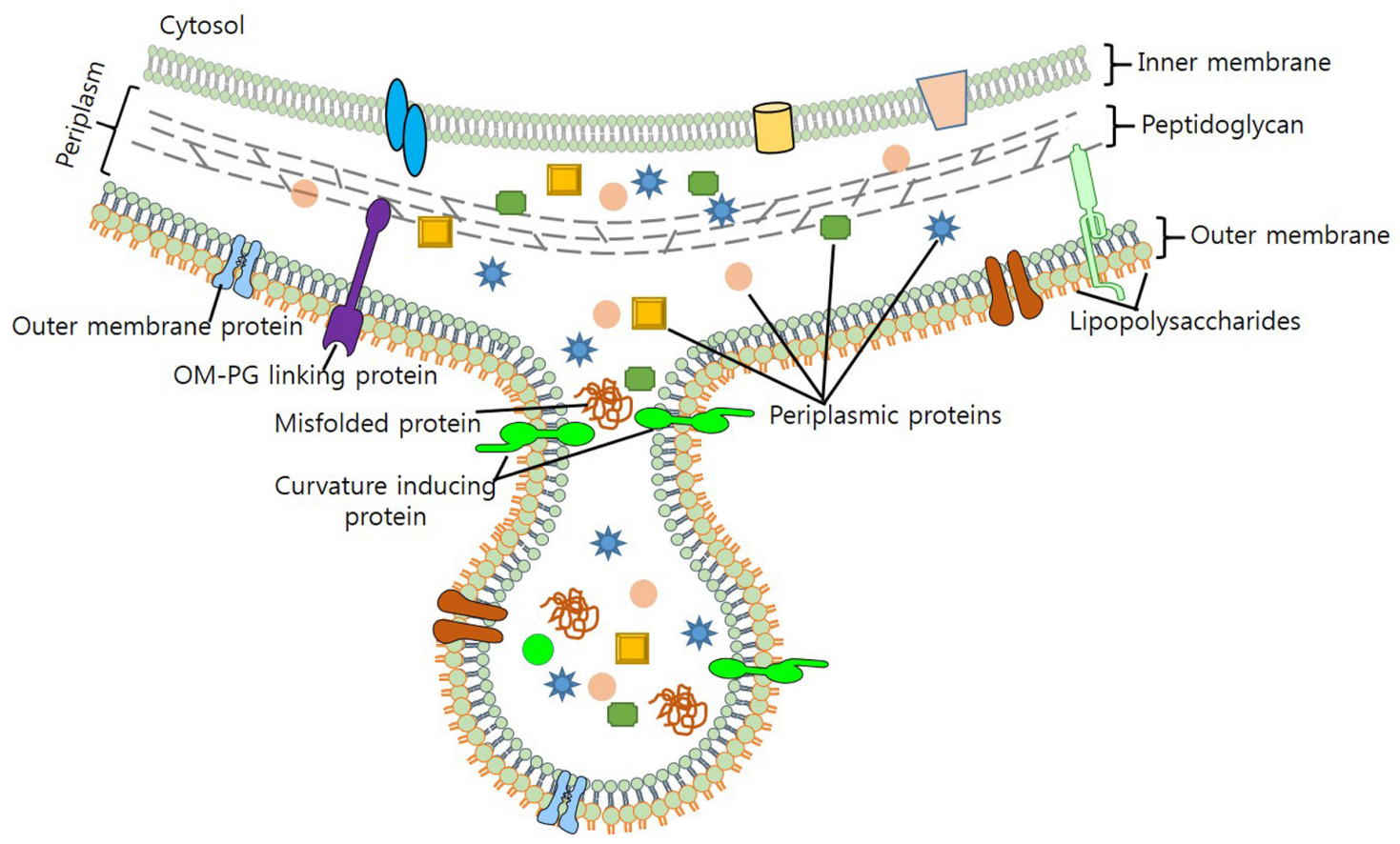

FIGURE 1 | Biogenesis of OMV production in bacteria. Figure depicts the composition of OMV, cargo selection and loading as part of OMVs.

Mashburn and Whiteley (2005) proposed that enrichment of OM with phospholipids, LPS and other specific molecules, brings curvature changes in OM that leads to OMV production (Mashburn and Whiteley, 2005). Work done on P. aeruginosa unveils membrane curvature transformations brought by the membrane insertion of a quorum sensing molecule PQS (2-heptyl-3-hydroxy-4-quinolone), results in OMV production (Mashburn-Warren et al., 2009; Schertzer and Whiteley, 2012). Sequestration of positively charged compounds and destabilization of $\mathrm{Mg}^{2+}$ and $\mathrm{Ca}^{2+}$ salt bridges by PQS, increases anionic repulsion of LPS molecules; thereby increasing OMV production (Mashburn and Whiteley, 2005). Enhanced OMV production has been observed by the addition of chelating agents (EDTA), however, addition of $\mathrm{Mg}^{2+}$ to $P$. aeruginosa results in the antagonist effect (Mashburn and Whiteley, 2005; Lee et al., 2016). On the contrary, proteins of OM such as OmpA, TolA/B (Tol-Pal), YbgF, and LppAB - which stabilize OM by enhancing protein-protein or protein-PG interactions - also contribute to the biogenesis of OMVs (Schwechheimer et al., 2013). Moreover, stress such as high temperature, presence of contaminants such as antibiotics also increases OMV production (Kulp and Kuehn, 2010; MacDonald and Kuehn, 2012).

\section{COMPOSITION OF OMVs}

Analysis of OMVs, purified by density gradient centrifugation revealed their constituents i-e. proteins and lipids of OM, periplasm, along with different cytoplasmic components. Regarded as distinct cellular entities, following section summarizes the information about the constituents of OMVs, which includes proteins, lipids and other entities:

\section{Proteins}

Study of OMVs reveal abundance of OM proteins (OMPs; OmpA, OmpC, and OmpF), periplasmic proteins (AcrA and alkaline phosphatase) and a series of virulence factors involved in the adhesion and invasion of host tissues. With advancements in the MS-based proteomic profiling technologies, identification of more than 3500 proteins - belonging to diverse functional categories - became possible (Kim et al., 2013). Evidence suggests that protein cellular localization greatly affects its inclusion to OMVs, as observed for $H$. pylori and Serratia marcescens (Olofsson et al., 2010; McMahon et al., 2012). Periplasmic proteins associated with the inner leaflet of $\mathrm{OM}$ exhibit increased incorporation within OMVs, in comparison with the proteins that are tightly bound to inner membrane. Although majority of OMPs from H. pylori load as cargo to OMVs, an anomalous behavior in cargo loading behavior in S. marcescens is also observed (Olofsson et al., 2010; McMahon et al., 2012). In S. marcescens, proteins such as Omps, maltoporin, and TolC, that show abundance on OM, goes undetected in OMVs. Failure in export of MipA in S. marcescens, as a part of OMVs and vice versa, goes unnoticed in the OM (McMahon et al., 2012). Although, actual mechanism for this mysterious behavior remains elusive, the decision of secretion or cellular retention is believed to occur via a series of protein and lipid recruitment factors. Contrastingly, shiga toxin of $S$. dysenteriae promotes its secretion by enhancing OMV production (Yokoyama et al., 2000). Upholding strainspecific characteristics, preferential packaging of proteins to 
OMVs is influenced by protein content of OMVs. As packaging process depends on the concentration ratio of OMV with its cellular contents, enrichment of proteins to OMVs occurs when protein contents of OMVs, that are normalized to OM, are significantly higher with respect to their cellular concentration (Bonnington and Kuehn, 2014).

\section{Lipids}

Lipids represent important structural components of Gramnegative OMVs. Sharing similarity with OM (Chowdhury and Jagannadham, 2013; Kulkarni and Jagannadham, 2014), there are reports of some lipids being present in OMVs but not as part of OM (Kato et al., 2002). Horstman and Kuehn (2000) reported that enterotoxigenic E. coli OMVs have glycerophospholipids, phosphatidylglycerol, phosphatidylethanolamine, and cardiolipin as its major lipids, which are associated with the curvature of OMVs (Horstman and Kuehn, 2000). Chowdhury and Jagannadham, (2013) revealed fine structural characterization of OMVs while performing mass spectrometric (MS) studies on $P$. syringae (Chowdhury and Jagannadham, 2013). They found, phosphatidylglycerol and phosphatidylethanolamine are the major lipid components in the OMVs. Similarly, other studies also reveal that phosphatidylglycerols are major constituents in OMVs, however, it was also seen that phosphatidylethanolamines compose the major portion of OM (Tashiro et al., 2011). Moreover, higher proportion of saturated fatty acids in OMVs attributes them with a rigid structure.

Performing functions of adhesion in biofilms, LPS (characteristic of Gram negative $\mathrm{OM}$ ) are also present as component to OMVs. Similar to proteins, only a fractional amount of parent LPS are present in the OMVs (Kulkarni and Jagannadham, 2014). Expressing two types of O-antigen side chains, $P$. aeruginosa show enrichment of negatively charged B-band forms of LPS in OMVs, compared to neutral A-band (Kadurugamuwa and Beveridge, 1995). Enrichment of OMVs with B-band LPS is believed to be the consequence of the charge repulsive forces between adjacent B-band molecules in OM. Contrastingly, enrichment with A-band LPS of OMVs has been observed in the dental pathogen, Porphyromonas gingivalis (Haurat et al., 2011).

\section{Nucleic Acids}

Outer Membrane Vesicles carry both luminal and surface associated DNA. A clear distinction between them arises on DNase treatment; luminal DNA being resistant persists even after the treatment process (Renelli et al., 2004). With this, several different forms of luminal DNA have been reported from E. coli, $N$. gonorrhoeae, $P$. aeruginosa, and $H$. influenza (Dorward and Garon, 1989; Kolling and Matthews, 1999; Mashburn-Warren and Whiteley, 2006; Lee et al., 2008). In addition to DNA, RNA, plasmid and DNA of phage and chromosomal DNA, has also been reported in OMVs. Although actual mechanisms of nucleic acid incorporation remain unclear, but it is believed that nucleic acid incorporation into the interior of OMVs happens from the lysed remains of cells that are present in the milieu, during the process of biogenesis (Yaron et al., 2000; Renelli et al., 2004).
Sorting of individual cellular components and their loading as cargo, controls composition and distribution of OMVs, and as such their specificity in counteracting the immune defense system of host. Acting as a signature to bacterial fitness, characteristic enrichment of proteins, lipids and nucleic acids to lumen or localization to OMV membrane, sheds light on the physiological functioning of OMVs and their association in increasing the bacterial survivability in their niche.

\section{FUNCTION OF OMVs}

Outer Membrane Vesicles have characteristics that enable them to mediate transfer of DNA fragments, autolysins, cytotoxins, virulence factors and a variety of other biomolecules (Alaniz et al., 2007; Furuta et al., 2009; Biller et al., 2014; Fulsundar et al., 2014). Their secretion helps bacteria in establishing inter- and intraspecies communication and also strengthens the interaction with the host. Among the prominent roles in diverse physiological and pathological functions, OMVs have been recognized for their role in acquisition of nutrients, stress responses and delivery of toxins, adhesion and virulence factors to evade host defense system (Figure 2).

\section{Bacterial Mortality and Nutrient Acquisition}

Differences in peptidoglycan composition makes bacteria prone to death by OMVs. The killing effect is prominent for bacterial types that show similarity in peptidoglycan composition, as that of OMV donors (Kulkarni and Jagannadham, 2014). Neutralization of bacteria is compromised due to the presence of similar degradative enzymes in OMVs and bacteria, making bacteria less susceptible to degradation. Moreover, fusion of OMVs with a non-self-strain increases their susceptibility toward degradative enzyme machinery (Beveridge, 1999). The enzyme cargo of OMVs administers bacteria with the capability of making distinction between self and non-self populations, enabling target specific killing of non-self-bacteria (Vasilyeva et al., 2008). An excellent example of this system is operational in the Lysobacter sp. - that secretes endopeptidase L5 - which is capable of degrading competing Gram-negative bacteria (Vasilyeva et al., 2008). A similar mechanism also operates for PG hydrolases. OMVs that possess PG hydrolases produce extermination effects after making a clear distinction for non-self-bacteria (Kadurugamuwa and Beveridge, 1996; MacDonald and Kuehn, 2012).

Of the versatile roles, packaging of enzymes such as proteases and glycosidases as cargoes to OMVs, plays a prominent role in the acquisition of nutrients for bacterial communities. OMV associated DNA and proteins function as a source of carbon and nitrogen during the bacterial growth. OMVs of Myxococcus xanthus carry alkaline phosphatase, which upon act on competitive bacteria cause release of phosphate that promotes development of multicellular community (Evans et al., 2012; Berleman et al., 2014). Phosphoenolpyruvate, a catalytic product of OMVs carrying enolase, converts plasminogen to plasmin. Phosphoenolpyruvate also aids in the bacterial colonization of the 


\begin{tabular}{|l|}
\hline Major ones \\
(1) Host immune suppression \\
(2) Sharing of resistance \\
determinants \\
(3) Enhanced biofilm \\
formation \\
(4) Relieving stress \\
(5) Nutrient acquisition \\
(6) Trapping AMPs \\
\hline
\end{tabular}

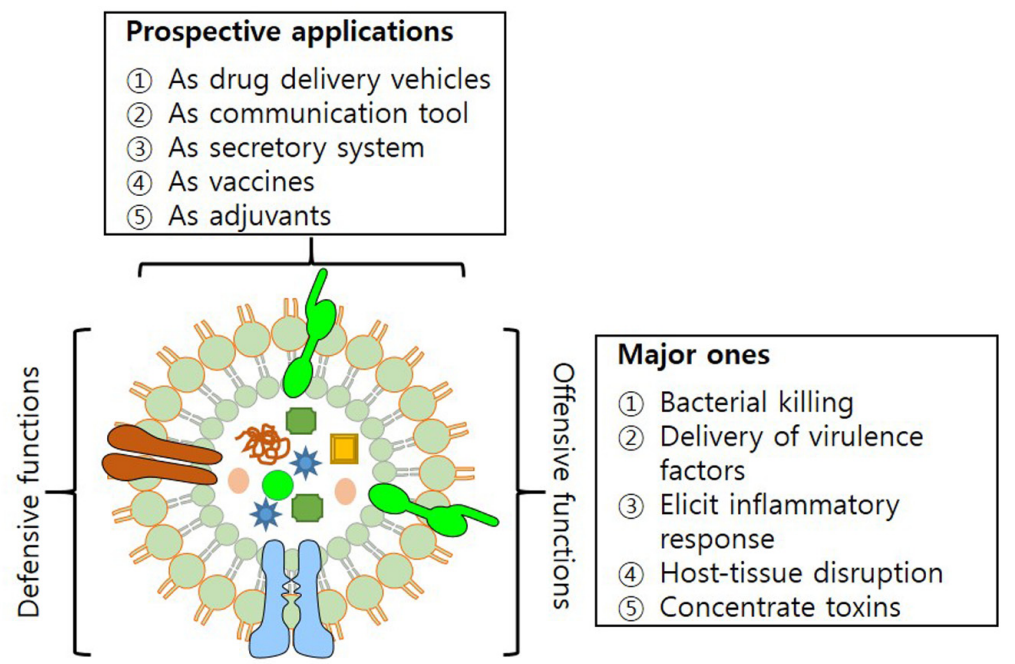

FIGURE 2 | Structure of OMV. Figure illustrating offensive and defensive roles of OMVs utilized in bacteria-bacteria and bacteria-host interactions; and their potential applications.

host, following the degradation of matrix proteins (Toledo et al., 2012). The scarcity of metal ions in the bacterial habitats leads to inter- and intra-species competition (Kulp and Kuehn, 2010). In addition to serving as an arsenal in interspecies competition, enrichment of OMVs with rare metal ions makes them available for easy disposal to microbial use.

\section{Stress Response and Biofilm Formation}

Mutation in the stress responsive genes increases production of OMVs in the bacteria. Exposure of cells to environmental contaminants (antibiotics) has potentially evolved bacterial OMVs, either with multidrug efflux pumps capabilities or with ability to catalyze degradation by sequestering antibiotics from the extracellular milieu (Ciofu et al., 2000; Manning and Kuehn, 2011). Acting as nutrient sensors and transporters of essential molecules, enhanced expression of surface receptors and $\mathrm{ABC}$ transporter in OMVs increases bacterial survival. The release of unfolded and misfolded proteins to OMVs gives an impression of its development, by sensing a stress responsive state (Baumgarten et al., 2012).

Biofilms are surface adhering structures produced in response to stress by bacteria (Kulp and Kuehn, 2010; Manning and Kuehn, 2011). Matrix assisted biofilms contain polysaccharides, lipids, nucleic acids and protein entities like flagella, pili and OMVs. OMVs mediate delivery of growth factors and components of the extracellular matrix (Schooling and Beveridge, 2006; Klimentova and Stulik, 2015). Release of exopolysaccharides through OMVs increases co-aggregation of cells in the biofilms. Shift from free living to the sedentary state of the bacterial population in biofilms protects cells from desiccation, starvation and adverse effects of antimicrobial agents (Klimentova and Stulik, 2015). Production of OMV helps bacteria to overcome the effects of antimicrobial peptides. Acting as carriage of resistant determinants like $\beta$-lactams, and enzymes such as protease, endopeptidases, etc.,
OMVs give survival advantage to bacteria due to antibiotic resistance traits via biofilms, thereby protects bacteria from antibiotic carnage (Beveridge et al., 1997). Represented as decoy entities, vesicle associated multidrug efflux pumps contribute in transient survival of susceptible bacteria in their surroundings. Association of OMVs with the biofilms of $P$. aeruginosa has been already reported (Beveridge et al. (1997), subsequent studies suggest intimidate relation between stress and the production of OMV on observing increase in OMV production during stress conditions (Beveridge et al., 1997; Baumgarten et al., 2012; Fulsundar et al., 2014).

\section{Secretion of Toxins, Adhesions, and Virulence Factors}

Interaction of bacteria with host triggers release of OMVs, carrying proteins (OspA and $\mathrm{OspB}$ in B. burgdorferi) and other adhesion molecules (SabA, BabA, and VacA in H. Pylori, UspA1 in $M$. catarrhalis and aminopeptidase in $P$. aeruginosa) on their surface (MacDonald and Kuehn, 2012). OMVs acting as a bridge to increase adhesion of bacteria with the host tissues. They are also known to increase adherence of bacteria with epithelial linings of gut or the respiratory tract which helps bacteria resist their physical elimination. Association of OMVs with pathogen associated molecular patterns (PAMPs) such as LPS and porins, mediates strong immune response in endothelial cells and induces expression of pattern recognizing receptors on macrophages (Ellis and Kuehn, 2010; Kim et al., 2013). OMVs associated toxins such as leukotoxin, LPS, and ClyA are more potent than their soluble forms (Wai et al., 2003; Kuehn and Kesty, 2005). Secretion of shiga toxin from enterohemorrhagic E. coli O157:H7 and stx1 and stx2 of S. dysenteriae as cargo to OMVs efficiently inhibits eukaryotic protein synthesis (Yokoyama et al., 2000; Dutta et al., 2004). OMVs harboring multiple virulence factors such as $\mathrm{Cif}, \mathrm{PlcH}$, 
LPS, and alkaline phosphatase produce pronounced effect on host cells (Bomberger et al., 2009; Ellis and Kuehn, 2010). Secretion of toxins and virulence factors help bacteria to invade host cells, hijack host machinery for nutrient acquisition and also evade host defense system by modulating host immune response, which is pivotal for their fecundity and survival in the host.

\section{Invasion of Host and Modulation of Immune Defense}

It is well established that OMVs have diverse biological functions i-e. from short range intercellular communications, to their long distance mode of action. They also perform immunomodulatory function by regulating delivery of different constituents to recipient cells (Corrado et al., 2013). Internalization of OMVs is achieved by four different pathways i-e. Macropinocytosis, Clathrin, Caveolin, and Lipid raft mediated endocytosis. Macropinocytosis is an actin driven process, which allows internalization of OMVs after sampling of extracellular medium at the cell surface. Macropinocytosis is reported from S. flexneri, where it helps to establish infection on host tissues (O'Donoghue and Krachler, 2016; Weiner et al., 2016). Clathrin mediated endocytosis via, clathrin coated pits occurs following ligand binding to cell surface receptor, triggering internalization of OVMs (Rewatkar et al., 2015). Unlike macropinocytosis that allows internalization of vesicles of $1 \mu \mathrm{m}$ diameter, clathrin dependent endocytosis allows internalization of cargo, with a maximum of $120 \mathrm{~nm}$ diameter. Clathrin mediated endocytosis is adapted for internalization of shiga toxin, CT, and cytotoxic virulence factor, VacA of H. pylori (Boisvert and Duncan, 2008; Parker et al., 2010). Caveolin mediated endocytosis occurs as cave shaped invagination $(80 \mathrm{~nm})$ of membrane rich in cholesterol, sphingolipids, and caveolin. Despite sluggish internalization speed (five times less than clathrin mediated), it leads in the efficient delivery of cargo to the cytosol (Ritter et al., 1995; Mulcahy et al., 2014; Rewatkar et al., 2015). This type of transfer is utilized by $H$. influenza. Lipid raft (plasma membrane domains enriched in cholesterol and sphingolipids) mediated endocytosis is known for its involvement in the OMVs entry to host cells (Furuta et al., 2009; Jin et al., 2011; Sharpe et al., 2011; Mulcahy et al., 2014; Mondal et al., 2016). It is hypothesized that clustering of cholesterol rich regions causes curvature in membrane that drives movement of molecules as invagination (90nm) to host cell.

\section{CONCLUSION}

Outer Membrane Vesicles are produced by a series of pathogenic and non-pathogenic bacteria. Devoid of cytosolic components, their cargo content (proteins and lipids) shows high similarity

\section{REFERENCES}

Alaniz, R. C., Deatherage, B. L., Lara, J. C., and Cookson, B. T. (2007). Membrane vesicles are immunogenic facsimiles of Salmonella typhimurium that potently activate dendritic cells, prime $\mathrm{B}$ and $\mathrm{T}$ cell responses, and stimulate protective to the OM of the bacteria, from where they originate. Acting as a secretory system, molecules of definite composition destined to different cellular localizations are delivered in an active form, protected by membranous sheath. OMVs are associated with the release of molecules mediating bacterial survival in free state or in biofilm structures, thereby allowing maintenance of virulence, stress release, transformation along with adherence and colonization of bacteria to different hosts. Additionally, they play a significant role in bacterial adaptation by harboring enzymatic machinery for breakdown of complex material into nutrients and consequentially making it available for transportation into cells. With ability to shuttle molecules between cells; they facilitate cell-to-cell communication in a variety of biological processes. Their contribution in processes such as nutrient acquisition, intercellular communication, defense, and regulators of cellular niche has raised considerable interest of scientific fraternity for studying their role as a carrier in the delivery of therapeutics.

Outer Membrane Vesicles are speculated to modulate many physiological and pathological procedures. Exploiting their physiological characteristics, delivery of a series of therapeutic cargos (siRNA, microRNA, and proteins) to tissues has been already achieved (Raposo and Stoorvogel, 2013). Bioengineering aimed to achieve target specific delivery of therapeutics has also been exploited by designing potent liposomal nanocarriers. With a lipid bilayer topology, encapsulation of amphipathic therapeutics by liposomes, provides them a longer life span, besides increasing their stability with reduced side effects (Ozpolat et al., 2014). With maximum use in carrying drugs, liposomal encapsulated chemotherapeutic agents, such as doxorubicin shows its increased accumulation in tumor and significantly reduced toxicity, when compared with the use of free doxorubicin (Petros and DeSimone, 2010). The facilitation in the release of therapeutic cargo under specific conditions, calls for the bioengineering of liposomes based nanocarriers on the footprints of OMVs, to achieve better targeting and increased uptake of therapeutics.

\section{AUTHOR CONTRIBUTIONS}

AJ conceived the idea and contributed to writing of the manuscript.

\section{ACKNOWLEDGMENT}

Author extends thanks to colleagues Drs. Safikur Rehman, Tufail Bashir, and Mudsser Azam for criticism that helped to improve the quality of contents in the perspective of broader audience.

immunity in vivo. J. Immunol. 179, 7692-7701. doi: 10.4049/jimmunol.179.11. 7692

Allan, N. D., Kooi, C., Sokol, P. A., and Beveridge, T. J. (2003). Putative virulence factors are released in association with membrane vesicles from Burkholderia cepacia. Can. J. Microbiol. 49, 613-624. doi: 10.1139/w03-078 
Altindis, E., Fu, Y., and Mekalanos, J. J. (2014). Proteomic analysis of Vibrio cholerae outer membrane vesicles. Proc. Natl. Acad. Sci. U.S.A. 111, E1548-E1556. doi: 10.1073/pnas.1403683111

Bauman, S. J., and Kuehn, M. J. (2006). Purification of outer membrane vesicles from Pseudomonas aeruginosa and their activation of an IL-8 response. Microbes Infect. 8, 2400-2408. doi: 10.1016/j.micinf.2006.05.001

Baumgarten, T., Sperling, S., Seifert, J., Von Bergen, M., Steiniger, F., Wick, L. Y., et al. (2012). Membrane vesicle formation as a multiplestress response mechanism enhances Pseudomonas putida DOT-T1E cell surface hydrophobicity and biofilm formation. Appl. Environ. Microbiol. 78, 6217-6224. doi: 10.1128/AEM.01525-12

Bergman, M. A., Cummings, L. A., Barrett, S. L., Smith, K. D., Lara, J. C., Aderem, A., et al. (2005). CD4+ T cells and toll-like receptors recognize Salmonella antigens expressed in bacterial surface organelles. Infect. Immun. 73, 1350-1356. doi: 10.1128/IAI.73.3.1350-1356.2005

Berleman, J. E., Allen, S., Danielewicz, M. A., Remis, J. P., Gorur, A., Cunha, J., et al. (2014). The lethal cargo of Myxococcus xanthus outer membrane vesicles. Front. Microbiol. 5:474. doi: 10.3389/fmicb.2014.00474

Bernadac, A., Gavioli, M., Lazzaroni, J. C., Raina, S., and Lloubes, R. (1998). Escherichia coli tol-pal mutants form outer membrane vesicles. J. Bacteriol. 180, 4872-4878.

Beveridge, T. J. (1999). Structures of gram-negative cell walls and their derived membrane vesicles. J. Bacteriol. 181, 4725-4733.

Beveridge, T. J., Makin, S. A., Kadurugamuwa, J. L., and Li, Z. (1997). Interactions between biofilms and the environment. FEMS Microbiol. Rev. 20, 291-303. doi: 10.1111/j.1574-6976.1997.tb00315.x

Biller, S. J., Schubotz, F., Roggensack, S. E., Thompson, A. W., Summons, R. E., and Chisholm, S. W. (2014). Bacterial vesicles in marine ecosystems. Science 343, 183-186. doi: 10.1126/science.1243457

Bishop, A. L., Schild, S., Patimalla, B., Klein, B., and Camilli, A. (2010). Mucosal immunization with Vibrio cholerae outer membrane vesicles provides maternal protection mediated by antilipopolysaccharide antibodies that inhibit bacterial motility. Infect. Immun. 78, 4402-4420. doi: 10.1128/IAI.00398-10

Boisvert, H., and Duncan, M. J. (2008). Clathrin-dependent entry of a gingipain adhesin peptide and Porphyromonas gingivalis into host cells. Cell Microbiol. 10, 2538-2552. doi: 10.1111/j.1462-5822.2008.01228.x

Bomberger, J. M., Maceachran, D. P., Coutermarsh, B. A., Ye, S., O'toole, G. A., and Stanton, B. A. (2009). Long-distance delivery of bacterial virulence factors by Pseudomonas aeruginosa outer membrane vesicles. PLoS Pathog. 5:e1000382. doi: 10.1371 /journal.ppat.1000382

Bonnington, K. E., and Kuehn, M. J. (2014). Protein selection and export via outer membrane vesicles. Biochim. Biophys. Acta 1843, 1612-1619. doi: 10.1016/j. bbamcr.2013.12.011

Burdett, I. D., and Murray, R. G. (1974). Electron microscope study of septum formation in Escherichia coli strains B and B-r during synchronous growth. J. Bacteriol. 119, 1039-1056.

Cascales, E., Bernadac, A., Gavioli, M., Lazzaroni, J. C., and Lloubes, R. (2002). Pal lipoprotein of Escherichia coli plays a major role in outer membrane integrity. J. Bacteriol. 184, 754-759. doi: 10.1128/JB.184.3.754-759.2002

Chatterjee, D., and Chaudhuri, K. (2011). Association of cholera toxin with Vibrio cholerae outer membrane vesicles which are internalized by human intestinal epithelial cells. FEBS Lett. 585, 1357-1362. doi: 10.1016/j.febslet.2011. 04.017

Chattopadhyay, M. K., and Jaganandham, M. V. (2015). Vesicles-mediated resistance to antibiotics in bacteria. Front. Microbiol. 6:758. doi: 10.3389/fmicb. 2015.00758

Chi, B., Qi, M., and Kuramitsu, H. K. (2003). Role of dentilisin in Treponema denticola epithelial cell layer penetration. Res. Microbiol. 154, 637-643. doi: 10.1016/j.resmic.2003.08.001

Choi, D. S., Kim, D. K., Choi, S. J., Lee, J., Choi, J. P., Rho, S., et al. (2011). Proteomic analysis of outer membrane vesicles derived from Pseudomonas aeruginosa. Proteomics 11, 3424-3429. doi: 10.1002/pmic.201000212

Chowdhury, C., and Jagannadham, M. V. (2013). Virulence factors are released in association with outer membrane vesicles of Pseudomonas syringae pv. tomato T1 during normal growth. Biochim. Biophys. Acta 1834, 231-239. doi: 10.1016/ j.bbapap.2012.09.015

Ciofu, O., Beveridge, T. J., Kadurugamuwa, J., Walther-Rasmussen, J., and Hoiby, N. (2000). Chromosomal beta-lactamase is packaged into membrane vesicles and secreted from Pseudomonas aeruginosa. J. Antimicrob. Chemother. 45, 9-13. doi: $10.1093 / \mathrm{jac} / 45.1 .9$

Collins, B. S. (2011). Gram-negative outer membrane vesicles in vaccine development. Discov. Med. 12, 7-15.

Corrado, C., Raimondo, S., Chiesi, A., Ciccia, F., De Leo, G., and Alessandro, R. (2013). Exosomes as intercellular signaling organelles involved in health and disease: basic science and clinical applications. Int. J. Mol. Sci. 14, 5338-5366. doi: $10.3390 /$ ijms 14035338

Devoe, I. W., and Gilchrist, J. E. (1973). Release of endotoxin in the form of cell wall blebs during in vitro growth of Neisseria meningitidis. J. Exp. Med. 138, 1156-1167. doi: 10.1084/jem.138.5.1156

Dorward, D. W., and Garon, C. F. (1989). DNA-binding proteins in cells and membrane blebs of Neisseria gonorrhoeae. J. Bacteriol. 171, 4196-4201. doi: $10.1128 /$ jb.171.8.4196-4201.1989

Dorward, D. W., Schwan, T. G., and Garon, C. F. (1991). Immune capture and detection of Borrelia burgdorferi antigens in urine, blood, or tissues from infected ticks, mice, dogs, and humans. J. Clin. Microbiol. 29, 1162-1170.

Dutta, S., Iida, K., Takade, A., Meno, Y., Nair, G. B., and Yoshida, S. (2004). Release of Shiga toxin by membrane vesicles in Shigella dysenteriae serotype 1 strains and in vitro effects of antimicrobials on toxin production and release. Microbiol. Immunol. 48, 965-969. doi: 10.1111/j.1348-0421.2004.tb03626.x

Eddy, J. L., Gielda, L. M., Caulfield, A. J., Rangel, S. M., and Lathem, W. W. (2014). Production of outer membrane vesicles by the plague pathogen Yersinia pestis. PLOS ONE 9:e107002. doi: 10.1371/journal.pone.0107002

Eggert, U. S., Ruiz, N., Falcone, B. V., Branstrom, A. A., Goldman, R. C., Silhavy, T. J., et al. (2001). Genetic basis for activity differences between vancomycin and glycolipid derivatives of vancomycin. Science 294, 361-364. doi: 10.1126/ science. 1063611

Elhenawy, W., Bording-Jorgensen, M., Valguarnera, E., Haurat, M. F., Wine, E., and Feldman, M. F. (2016). LPS remodeling triggers formation of outer membrane vesicles in Salmonella. MBio 7:e00940-16. doi: 10.1128/mBio.00940-16

Ellis, T. N., and Kuehn, M. J. (2010). Virulence and immunomodulatory roles of bacterial outer membrane vesicles. Microbiol. Mol. Biol. Rev. 74, 81-94. doi: 10.1128/MMBR.00031-09

Ellis, T. N., Leiman, S. A., and Kuehn, M. J. (2010). Naturally produced outer membrane vesicles from Pseudomonas aeruginosa elicit a potent innate immune response via combined sensing of both lipopolysaccharide and protein components. Infect. Immun. 78, 3822-3831. doi: 10.1128/IAI.00433-10

Elmi, A., Watson, E., Sandu, P., Gundogdu, O., Mills, D. C., Inglis, N. F., et al. (2012). Campylobacter jejuni outer membrane vesicles play an important role in bacterial interactions with human intestinal epithelial cells. Infect. Immun. 80, 4089-4098. doi: 10.1128/IAI.00161-12

Evans, A. G., Davey, H. M., Cookson, A., Currinn, H., Cooke-Fox, G., Stanczyk, P. J., et al. (2012). Predatory activity of Myxococcus xanthus outer-membrane vesicles and properties of their hydrolase cargo. Microbiology 158, 2742-2752. doi: 10.1099/mic.0.060343-0

Fernandez-Moreira, E., Helbig, J. H., and Swanson, M. S. (2006). Membrane vesicles shed by Legionella pneumophila inhibit fusion of phagosomes with lysosomes. Infect. Immun. 74, 3285-3295. doi: 10.1128/IAI.01382-05

Ferrari, G., Garaguso, I., Adu-Bobie, J., Doro, F., Taddei, A. R., Biolchi, A., et al. (2006). Outer membrane vesicles from group B Neisseria meningitidis delta gna33 mutant: proteomic and immunological comparison with detergentderived outer membrane vesicles. Proteomics 6, 1856-1866. doi: 10.1002/pmic. 200500164

Fiocca, R., Necchi, V., Sommi, P., Ricci, V., Telford, J., Cover, T. L., et al. (1999). Release of Helicobacter pylori vacuolating cytotoxin by both a specific secretion pathway and budding of outer membrane vesicles. Uptake of released toxin and vesicles by gastric epithelium. J. Pathol. 188, 220-226. doi: 10.1002/(SICI)10969896(199906) 188:2<220::AID-PATH307>3.0.CO;2-C

Fulsundar, S., Harms, K., Flaten, G. E., Johnsen, P. J., Chopade, B. A., and Nielsen, K. M. (2014). Gene transfer potential of outer membrane vesicles of Acinetobacter baylyi and effects of stress on vesiculation. Appl. Environ. Microbiol. 80, 3469-3483. doi: 10.1128/AEM.04248-13

Furuta, N., Takeuchi, H., and Amano, A. (2009). Entry of Porphyromonas gingivalis outer membrane vesicles into epithelial cells causes cellular functional impairment. Infect. Immun. 77, 4761-4770. doi: 10.1128/IAI.00841-09

Galka, F., Wai, S. N., Kusch, H., Engelmann, S., Hecker, M., Schmeck, B., et al. (2008). Proteomic characterization of the whole secretome of Legionella 
pneumophila and functional analysis of outer membrane vesicles. Infect. Immun. 76, 1825-1836. doi: 10.1128/IAI.01396-07

Haurat, M. F., Aduse-Opoku, J., Rangarajan, M., Dorobantu, L., Gray, M. R., Curtis, M. A., et al. (2011). Selective sorting of cargo proteins into bacterial membrane vesicles. J. Biol. Chem. 286, 1269-1276. doi: 10.1074/jbc.M110.185744

Haurat, M. F., Elhenawy, W., and Feldman, M. F. (2015). Prokaryotic membrane vesicles: new insights on biogenesis and biological roles. Biol. Chem. 396, 95-109. doi: 10.1515/hsz-2014-0183

Hoekstra, D., Van Der Laan, J. W., De Leij, L., and Witholt, B. (1976). Release of outer membrane fragments from normally growing Escherichia coli. Biochim. Biophys. Acta 455, 889-899. doi: 10.1016/0005-2736(76)90058-4

Horstman, A. L., and Kuehn, M. J. (2000). Enterotoxigenic Escherichia coli secretes active heat-labile enterotoxin via outer membrane vesicles. J. Biol. Chem. 275, 12489-12496. doi: 10.1074/jbc.275.17.12489

Hozbor, D., Rodriguez, M. E., Fernandez, J., Lagares, A., Guiso, N., and Yantorno, O. (1999). Release of outer membrane vesicles from Bordetella pertussis. Curr. Microbiol. 38, 273-278. doi: 10.1007/PL00006801

Jang, K. S., Sweredoski, M. J., Graham, R. L., Hess, S., and Clemons, W. M. Jr. (2014). Comprehensive proteomic profiling of outer membrane vesicles from Campylobacter jejuni. J. Proteomics 98, 90-98. doi: 10.1016/j.jprot.2013.12.014

Jin, J. S., Kwon, S. O., Moon, D. C., Gurung, M., Lee, J. H., Kim, S. I., et al. (2011). Acinetobacter baumannii secretes cytotoxic outer membrane protein A via outer membrane vesicles. PLoS ONE 6:e17027. doi: 10.1371/journal.pone. 0017027

Jun, S. H., Lee, J. H., Kim, B. R., Kim, S. I., Park, T. I., Lee, J. C., et al. (2013). Acinetobacter baumannii outer membrane vesicles elicit a potent innate immune response via membrane proteins. PLoS ONE 8:e71751. doi: 10.1371/ journal.pone.0071751

Kadurugamuwa, J. L., and Beveridge, T. J. (1995). Virulence factors are released from Pseudomonas aeruginosa in association with membrane vesicles during normal growth and exposure to gentamicin: a novel mechanism of enzyme secretion. J. Bacteriol. 177, 3998-4008. doi: 10.1128/jb.177.14.3998-4008.1995

Kadurugamuwa, J. L., and Beveridge, T. J. (1996). Bacteriolytic effect of membrane vesicles from Pseudomonas aeruginosa on other bacteria including pathogens: conceptually new antibiotics. J. Bacteriol. 178, 2767-2774. doi: 10.1128/jb.178. 10.2767-2774.1996

Kadurugamuwa, J. L., and Beveridge, T. J. (1998). Delivery of the non-membranepermeative antibiotic gentamicin into mammalian cells by using Shigella flexneri membrane vesicles. Antimicrob. Agents Chemother. 42, 1476-1483.

Kadurugamuwa, J. L., and Beveridge, T. J. (1999). Membrane vesicles derived from Pseudomonas aeruginosa and Shigella flexneri can be integrated into the surfaces of other gram-negative bacteria. Microbiology 145(Pt 8), 2051-2060. doi: 10.1099/13500872-145-8-2051

Kato, S., Kowashi, Y., and Demuth, D. R. (2002). Outer membrane-like vesicles secreted by Actinobacillus actinomycetemcomitans are enriched in leukotoxin. Microb. Pathog. 32, 1-13. doi: 10.1006/mpat.2001.0474

Keenan, J., Day, T., Neal, S., Cook, B., Perez-Perez, G., Allardyce, R., et al. (2000). A role for the bacterial outer membrane in the pathogenesis of Helicobacter pylori infection. FEMS Microbiol. Lett. 182, 259-264. doi: 10.1111/j.1574-6968. 2000.tb08905.x

Kim, Y. S., Choi, E. J., Lee, W. H., Choi, S. J., Roh, T. Y., Park, J., et al. (2013). Extracellular vesicles, especially derived from Gram-negative bacteria, in indoor dust induce neutrophilic pulmonary inflammation associated with both Th1 and Th17 cell responses. Clin. Exp. Allergy 43, 443-454. doi: 10.1111/cea.12085

Klimentova, J., and Stulik, J. (2015). Methods of isolation and purification of outer membrane vesicles from gram-negative bacteria. Microbiol. Res. 170, 1-9. doi: $10.1016 /$ j.micres.2014.09.006

Koeppen, K., Hampton, T. H., Jarek, M., Scharfe, M., Gerber, S. A., Mielcarz, D. W., et al. (2016). A novel mechanism of host-pathogen interaction through sRNA in bacterial outer membrane vesicles. PLoS Pathog. 12:e1005672. doi: 10.1371/journal.ppat.1005672

Kolling, G. L., and Matthews, K. R. (1999). Export of virulence genes and Shiga toxin by membrane vesicles of Escherichia coli O157:H7. Appl. Environ. Microbiol. 65, 1843-1848.

Kothary, M. H., Gopinath, G. R., Gangiredla, J., Rallabhandi, P. V., Harrison, L. M., Yan, Q. Q., et al. (2017). Analysis and characterization of proteins associated with outer membrane vesicles secreted by Cronobacter spp. Front. Microbiol. 8:134. doi: 10.3389/fmicb.2017.00134
Kuehn, M. J., and Kesty, N. C. (2005). Bacterial outer membrane vesicles and the host-pathogen interaction. Genes Dev. 19, 2645-2655. doi: 10.1101/gad.1299905

Kulkarni, H. M., and Jagannadham, M. V. (2014). Biogenesis and multifaceted roles of outer membrane vesicles from Gram-negative bacteria. Microbiology 160, 2109-2121. doi: 10.1099/mic.0.079400-0

Kulp, A., and Kuehn, M. J. (2010). Biological functions and biogenesis of secreted bacterial outer membrane vesicles. Annu. Rev. Microbiol. 64, 163-184. doi: 10.1146/annurev.micro.091208.073413

Kwon, S. O., Gho, Y. S., Lee, J. C., and Kim, S. I. (2009). Proteome analysis of outer membrane vesicles from a clinical Acinetobacter baumannii isolate. FEMS Microbiol. Lett. 297, 150-156. doi: 10.1111/j.1574-6968.2009.01669.x

Lee, E. Y., Choi, D. S., Kim, K. P., and Gho, Y. S. (2008). Proteomics in gramnegative bacterial outer membrane vesicles. Mass Spectrom. Rev. 27, 535-555. doi: $10.1002 /$ mas. 20175

Lee, J., Kim, O. Y., and Gho, Y. S. (2016). Proteomic profiling of Gram-negative bacterial outer membrane vesicles: current perspectives. Proteomics Clin. Appl. 10, 897-909. doi: 10.1002/prca.201600032

Li, Z., Clarke, A. J., and Beveridge, T. J. (1998). Gram-negative bacteria produce membrane vesicles which are capable of killing other bacteria. J. Bacteriol. 180, 5478-5483.

Lindmark, B., Rompikuntal, P. K., Vaitkevicius, K., Song, T., Mizunoe, Y., Uhlin, B. E., et al. (2009). Outer membrane vesicle-mediated release of cytolethal distending toxin (CDT) from Campylobacter jejuni. BMC Microbiol. 9:220. doi: 10.1186/1471-2180-9-220

MacDonald, I. A., and Kuehn, M. J. (2012). Offense and defense: microbial membrane vesicles play both ways. Res. Microbiol. 163, 607-618. doi: 10.1016/j. resmic.2012.10.020

Manning, A. J., and Kuehn, M. J. (2011). Contribution of bacterial outer membrane vesicles to innate bacterial defense. BMC Microbiol. 11:258. doi: 10.1186/14712180-11-258

Manning, A. J., and Kuehn, M. J. (2013). Functional advantages conferred by extracellular prokaryotic membrane vesicles. J. Mol. Microbiol. Biotechnol. 23, 131-141. doi: 10.1159/000346548

Mashburn, L. M., and Whiteley, M. (2005). Membrane vesicles traffic signals and facilitate group activities in a prokaryote. Nature 437, 422-425. doi: 10.1038/ nature 03925

Mashburn-Warren, L., Howe, J., Brandenburg, K., and Whiteley, M. (2009). Structural requirements of the Pseudomonas quinolone signal for membrane vesicle stimulation. J. Bacteriol. 191, 3411-3414. doi: 10.1128/JB.00052-09

Mashburn-Warren, L., Howe, J., Garidel, P., Richter, W., Steiniger, F., Roessle, M., et al. (2008). Interaction of quorum signals with outer membrane lipids: insights into prokaryotic membrane vesicle formation. Mol. Microbiol. 69, 491-502. doi: $10.1111 / j .1365-2958.2008 .06302 . x$

Mashburn-Warren, L. M., and Whiteley, M. (2006). Special delivery: vesicle trafficking in prokaryotes. Mol. Microbiol. 61, 839-846. doi: 10.1111/j.13652958.2006.05272.x

Massari, P., Gunawardana, J., Liu, X., and Wetzler, L. M. (2010). Meningococcal porin PorB prevents cellular apoptosis in a toll-like receptor 2- and NFkappaB-independent manner. Infect. Immun. 78, 994-1003. doi: 10.1128/IAI. 00156-09

McBroom, A. J., and Kuehn, M. J. (2007). Release of outer membrane vesicles by Gram-negative bacteria is a novel envelope stress response. Mol. Microbiol. 63, 545-558. doi: 10.1111/j.1365-2958.2006.05522.x

McCaig, W. D., Koller, A., and Thanassi, D. G. (2013). Production of outer membrane vesicles and outer membrane tubes by Francisella novicida. J. Bacteriol. 195, 1120-1132. doi: 10.1128/JB.02007-12

McMahon, K. J., Castelli, M. E., Garcia Vescovi, E., and Feldman, M. F. (2012). Biogenesis of outer membrane vesicles in Serratia marcescens is thermoregulated and can be induced by activation of the Rcs phosphorelay system. J. Bacteriol. 194, 3241-3249. doi: 10.1128/JB.00016-12

Mendez, J. A., Soares, N. C., Mateos, J., Gayoso, C., Rumbo, C., Aranda, J., et al. (2012). Extracellular proteome of a highly invasive multidrug-resistant clinical strain of Acinetobacter baumannii. J. Proteome Res. 11, 5678-5694. doi: 10.1021/ pr300496c

Mondal, A., Tapader, R., Chatterjee, N. S., Ghosh, A., Sinha, R., Koley, H., et al. (2016). Cytotoxic and inflammatory responses induced by outer membrane vesicle-associated biologically active proteases from Vibrio cholerae. Infect. Immun. 84, 1478-1490. doi: 10.1128/IAI.01365-15 
Moon, D. C., Choi, C. H., Lee, J. H., Choi, C. W., Kim, H. Y., Park, J. S., et al. (2012). Acinetobacter baumannii outer membrane protein A modulates the biogenesis of outer membrane vesicles. J. Microbiol 50, 155-160. doi: 10.1007/s12275-0121589-4

Mulcahy, L. A., Pink, R. C., and Carter, D. R. (2014). Routes and mechanisms of extracellular vesicle uptake. J. Extracell Vesicles 3, 24641. doi: 10.3402/jev.v3. 24641

Mullaney, E., Brown, P. A., Smith, S. M., Botting, C. H., Yamaoka, Y. Y., Terres, A. M., et al. (2009). Proteomic and functional characterization of the outer membrane vesicles from the gastric pathogen Helicobacter pylori. Proteomics Clin. Appl. 3, 785-796. doi: 10.1002/prca.200800192

Namork, E., and Brandtzaeg, P. (2002). Fatal meningococcal septicaemia with "blebbing" meningococcus. Lancet 360, 1741. doi: 10.1016/S0140-6736(02) 11721-1

O’Donoghue, E. J., and Krachler, A. M. (2016). Mechanisms of outer membrane vesicle entry into host cells. Cell Microbiol. 18, 1508-1517. doi: 10.1111/cmi. 12655

Olofsson, A., Vallstrom, A., Petzold, K., Tegtmeyer, N., Schleucher, J., Carlsson, S. et al. (2010). Biochemical and functional characterization of Helicobacter pylori vesicles. Mol. Microbiol. 77, 1539-1555. doi: 10.1111/j.1365-2958.2010.07307.x

Ozpolat, B., Sood, A. K., and Lopez-Berestein, G. (2014). Liposomal siRNA nanocarriers for cancer therapy. Adv. Drug Deliv. Rev. 66, 110-116. doi: 10.1016/j.addr.2013.12.008

Parker, H., Chitcholtan, K., Hampton, M. B., and Keenan, J. I. (2010). Uptake of Helicobacter pylori outer membrane vesicles by gastric epithelial cells. Infect. Immun. 78, 5054-5061. doi: 10.1128/IAI.00299-10

Petros, R. A., and DeSimone, J. M. (2010). Strategies in the design of nanoparticles for therapeutic applications. Nat. Rev. Drug Discov. 9, 615-627. doi: 10.1038/ $\operatorname{nrd} 2591$

Pettit, R. K., and Judd, R. C. (1992). The interaction of naturally elaborated blebs from serum-susceptible and serum-resistant strains of Neisseria gonorrhoeae with normal human serum. Mol. Microbiol. 6, 729-734. doi: 10.1111/j.13652958.1992.tb01522.x

Raposo, G., and Stoorvogel, W. (2013). Extracellular vesicles: exosomes, microvesicles, and friends. J. Cell Biol. 200, 373-383. doi: 10.1083/jcb.201211138

Raymond, B., and Bonsall, M. B. (2013). Cooperation and the evolutionary ecology of bacterial virulence: the Bacillus cereus group as a novel study system. Bioessays 35, 706-716. doi: 10.1002/bies.201300028

Renelli, M., Matias, V., Lo, R. Y., and Beveridge, T. J. (2004). DNA-containing membrane vesicles of Pseudomonas aeruginosa PAO1 and their genetic transformation potential. Microbiology 150, 2161-2169. doi: 10.1099/mic.0 26841-0

Rewatkar, P. V., Parton, R. G., Parekh, H. S., and Parat, M. O. (2015). Are caveolae a cellular entry route for non-viral therapeutic delivery systems? Adv. Drug Deliv. Rev. 91, 92-108. doi: 10.1016/j.addr.2015.01.003

Ritter, T. E., Fajardo, O., Matsue, H., Anderson, R. G., and Lacey, S. W. (1995). Folate receptors targeted to clathrin-coated pits cannot regulate vitamin uptake. Proc. Natl. Acad. Sci. U.S.A. 92, 3824-3828. doi: 10.1073/pnas.92.9.3824

Rolhion, N., Barnich, N., Claret, L., and Darfeuille-Michaud, A. (2005). Strong decrease in invasive ability and outer membrane vesicle release in Crohn's disease-associated adherent-invasive Escherichia coli strain LF82 with the yfgL gene deleted. J. Bacteriol. 187, 2286-2296. doi: 10.1128/JB.187.7.2286-2296. 2005

Rosen, G., Naor, R., Rahamim, E., Yishai, R., and Sela, M. N. (1995). Proteases of Treponema denticola outer sheath and extracellular vesicles. Infect. Immun. 63, 3973-3979.

Schertzer, J. W., and Whiteley, M. (2012). A bilayer-couple model of bacterial outer membrane vesicle biogenesis. MBio 3:e00297-11. doi: 10.1128/mBio.00297-11

Schooling, S. R., and Beveridge, T. J. (2006). Membrane vesicles: an overlooked component of the matrices of biofilms. J. Bacteriol. 188, 5945-5957. doi: 10.1128/JB.00257-06

Schwechheimer, C., and Kuehn, M. J. (2015). Outer-membrane vesicles from Gram-negative bacteria: biogenesis and functions. Nat. Rev. Microbiol. 13, 605-619. doi: 10.1038/nrmicro3525

Schwechheimer, C., Sullivan, C. J., and Kuehn, M. J. (2013). Envelope control of outer membrane vesicle production in Gram-negative bacteria. Biochemistry 52, 3031-3040. doi: 10.1021/bi400164t
Sharpe, S. W., Kuehn, M. J., and Mason, K. M. (2011). Elicitation of epithelial cell-derived immune effectors by outer membrane vesicles of nontypeable Haemophilus influenzae. Infect. Immun. 79, 4361-4369. doi: 10.1128/IAI. 05332-11

Shoberg, R. J., and Thomas, D. D. (1993). Specific adherence of Borrelia burgdorferi extracellular vesicles to human endothelial cells in culture. Infect. Immun. 61, 3892-3900.

Shoberg, R. J., and Thomas, D. D. (1995). Borrelia burgdorferi vesicle production occurs via a mechanism independent of immunoglobulin $\mathrm{M}$ involvement. Infect. Immun. 63, 4857-4861.

Sidhu, V. K., Vorholter, F. J., Niehaus, K., and Watt, S. A. (2008). Analysis of outer membrane vesicle associated proteins isolated from the plant pathogenic bacterium Xanthomonas campestris pv. campestris. BMC Microbiol. 8:87. doi: 10.1186/1471-2180-8-87

Spitzer, J., and Poolman, B. (2013). How crowded is the prokaryotic cytoplasm? FEBS Lett. 587, 2094-2098. doi: 10.1016/j.febslet.2013.05.051

Tan, T. T., Morgelin, M., Forsgren, A., and Riesbeck, K. (2007). Haemophilus influenzae survival during complement-mediated attacks is promoted by Moraxella catarrhalis outer membrane vesicles. J. Infect. Dis. 195, 1661-1670. doi: $10.1086 / 517611$

Tashiro, Y., Ichikawa, S., Shimizu, M., Toyofuku, M., Takaya, N., NakajimaKambe, T., et al. (2010). Variation of physiochemical properties and cell association activity of membrane vesicles with growth phase in Pseudomonas aeruginosa. Appl. Environ. Microbiol. 76, 3732-3739. doi: 10.1128/AEM. 02794-09

Tashiro, Y., Inagaki, A., Shimizu, M., Ichikawa, S., Takaya, N., Nakajima-Kambe, T., et al. (2011). Characterization of phospholipids in membrane vesicles derived from Pseudomonas aeruginosa. Biosci. Biotechnol. Biochem. 75, 605-607. doi: 10.1271/bbb.100754

Toledo, A., Coleman, J. L., Kuhlow, C. J., Crowley, J. T., and Benach, J. L. (2012). The enolase of Borrelia burgdorferi is a plasminogen receptor released in outer membrane vesicles. Infect. Immun. 80, 359-368. doi: 10.1128/IAI. 05836-11

Toyofuku, M., Roschitzki, B., Riedel, K., and Eberl, L. (2012). Identification of proteins associated with the Pseudomonas aeruginosa biofilm extracellular matrix. J. Proteome Res. 11, 4906-4915. doi: 10.1021/pr300395j

Turner, L., Praszkier, J., Hutton, M. L., Steer, D., Ramm, G., Kaparakis-Liaskos, M., et al. (2015). Increased outer membrane vesicle formation in a Helicobacter pylori tolB mutant. Helicobacter 20, 269-283. doi: 10.1111/hel.12196

Unal, C. M., Schaar, V., and Riesbeck, K. (2011). Bacterial outer membrane vesicles in disease and preventive medicine. Semin. Immunopathol. 33, 395-408. doi: 10.1007/s00281-010-0231-y

Van De Waterbeemd, B., Mommen, G. P., Pennings, J. L., Eppink, M. H., Wijffels, R. H., Van Der Pol, L. A., et al. (2013). Quantitative proteomics reveals distinct differences in the protein content of outer membrane vesicle vaccines. J. Proteome Res. 12, 1898-1908. doi: 10.1021/pr301208g

Vanaja, S. K., Russo, A. J., Behl, B., Banerjee, I., Yankova, M., Deshmukh, S. D. et al. (2016). Bacterial outer membrane vesicles mediate cytosolic localization of LPS and caspase-11 activation. Cell 165, 1106-1119. doi: 10.1016/j.cell.2016. 04.015

Vasilyeva, N. V., Tsfasman, I. M., Suzina, N. E., Stepnaya, O. A., and Kulaev, I. S. (2008). Secretion of bacteriolytic endopeptidase L5 of Lysobacter sp. XL1 into the medium by means of outer membrane vesicles. FEBS J. 275, 3827-3835. doi: 10.1111/j.1742-4658.2008.06530.x

Veith, P. D., Chen, Y. Y., Gorasia, D. G., Chen, D., Glew, M. D., O'brienSimpson, N. M., et al. (2014). Porphyromonas gingivalis outer membrane vesicles exclusively contain outer membrane and periplasmic proteins and carry a cargo enriched with virulence factors. J. Proteome Res. 13, 2420-2432. doi: $10.1021 / \mathrm{pr} 401227 \mathrm{e}$

Vidakovics, M. L., Jendholm, J., Morgelin, M., Mansson, A., Larsson, C., Cardell, L. O., et al. (2010). B cell activation by outer membrane vesicles-a novel virulence mechanism. PLoS Pathog. 6:e1000724. doi: 10.1371/journal.ppat. 1000724

Vipond, C., Suker, J., Jones, C., Tang, C., Feavers, I. M., and Wheeler, J. X. (2006). Proteomic analysis of a meningococcal outer membrane vesicle vaccine prepared from the group B strain NZ98/254. Proteomics 6, 3400-3413. doi: $10.1002 /$ pmic. 200500821 
Wai, S. N., Lindmark, B., Soderblom, T., Takade, A., Westermark, M., Oscarsson, J., et al. (2003). Vesicle-mediated export and assembly of pore-forming oligomers of the enterobacterial ClyA cytotoxin. Cell 115, 25-35. doi: 10.1016/S00928674(03)00754-2

Weiner, A., Mellouk, N., Lopez-Montero, N., Chang, Y. Y., Souque, C., Schmitt, C., et al. (2016). Macropinosomes are key players in early Shigella invasion and vacuolar escape in epithelial cells. PLoS Pathog. 12:e1005602. doi: 10.1371/ journal.ppat.1005602

Wensink, J., and Witholt, B. (1981). Outer-membrane vesicles released by normally growing Escherichia coli contain very little lipoprotein. Eur. J. Biochem. 116, 331-335. doi: 10.1111/j.1432-1033.1981.tb05338.x

Yaron, S., Kolling, G. L., Simon, L., and Matthews, K. R. (2000). Vesicle-mediated transfer of virulence genes from Escherichia coli O157:H7 to other enteric bacteria. Appl. Environ. Microbiol. 66, 4414-4420. doi: 10.1128/AEM.66.10. 4414-4420.2000
Yokoyama, K., Horii, T., Yamashino, T., Hashikawa, S., Barua, S., Hasegawa, T., et al. (2000). Production of shiga toxin by Escherichia coli measured with reference to the membrane vesicle-associated toxins. FEMS Microbiol. Lett. 192, 139-144. doi: 10.1111/j.1574-6968.2000.tb09372.x

Conflict of Interest Statement: The author declares that the research was conducted in the absence of any commercial or financial relationships that could be construed as a potential conflict of interest.

Copyright (c) 2017 Jan. This is an open-access article distributed under the terms of the Creative Commons Attribution License (CC BY). The use, distribution or reproduction in other forums is permitted, provided the original author(s) or licensor are credited and that the original publication in this journal is cited, in accordance with accepted academic practice. No use, distribution or reproduction is permitted which does not comply with these terms. 